\title{
Preferred Cognitive Learning Patterns (VAK) Among Secondary Students Admitted to King Saud University and its Effect on their Academic Achievement in Physics
}

\author{
Jehad Ali Almomani ${ }^{1}$ \\ ${ }^{1}$ Department of Self Development Skills, King Saud University, Kingdom of Saudi Arabia \\ Correspondence: Jehad Ali Almomani, Department of Self Development Skills, King Saud University, Kingdom \\ of Saudi Arabia.
}

Received: January 21, 2019

Accepted: February 28, 2019

Online Published: May 29, 2019

doi:10.5539/ies.v12n6p108

URL: https://doi.org/10.5539/ies.v12n6p108

\begin{abstract}
The aim of this study was to determine the preferred cognitive learning patterns among secondary students and their effect on their achievement in physics. To achieve the objective of the study, the researcher designed a scale of cognitive learning patterns (VAK) that consisted of (16) items, and after verifying its validity and reliability, it was applied to the sample of the study that consisted of (628) students randomly selected from the study population composed of secondary students admitted to King University Saud for the academic year 2017-2018. The results showed that there were statistically significant differences between the types of learning patterns preferred by students, that the majority of students preferred the visual pattern, followed by those who preferred the auditory pattern, while the kinesthetic pattern was the least favored by the students. The results also showed statistically significant differences in the learning patterns preferred by students attributed to the gender variable. It showed that males prefer the auditory pattern more than females, while females preferred the visual pattern more than males. There were no gender differences in their preference for the kinesthetic pattern. Moreover, Results related to the effect of the learning pattern on achievement showed a statistically significant effect of learning patterns on students' achievement in physics. It showed that the students who preferred the kinesthetic pattern are those who had the highest academic achievements, followed by the students who preferred the visual pattern, while the students who preferred the audio pattern were the least achievable students. Based on these results, the study recommended that teachers should be encouraged to diversify the strategies and methods of university teaching to suit the learning styles preferred by their students, especially the new students, to motivate them to learn in the university environment and to provide the training needs and requirements necessary to enable them to take into consideration the individual differences among their students when they identify educational goals, content, methods, and strategies.
\end{abstract}

Keywords: Cognitive Learning Patterns (VAK), academic achievement, Physics

\section{Introduction}

In the last years of the twentieth century, researchers in the educational and psychological fields have become increasingly interested in the educational patterns of learners in a serious attempt to develop education and improve its outcomes. To achieve this, it was necessary to take into account the individual differences between learners' patterns by diversifying appropriate teaching methods and strategies to help them learn effectively; since individuals during their development build their knowledge and experience and develop their multiple skills suitably, and their preferred learning styles. These patterns control their thinking about the stimuli and problems they face during their various life interactions; thus, it reflects their preferred ways of interacting with the environmental stimuli and experiences they encounter, and this is reflected in their methods of focusing on information, processing and retrieval. Knowing the learning styles that learners prefer allows them to choose teaching strategies that suit their preferences and plan for classroom activities in a way that satisfies the learners and improve their attitudes towards learning as well as their academic performance (Al-Nazeer, 2015; Alwan, 2012).

Based on the previous studies, it can be said that the learning pattern is the ability of the learner to absorb the experiences of learning by choosing the preferred method used to organize and address information and 
problems. The ways of interacting with these patterns are differed from one individual to another. In order to reconcile teaching methods with student learning patterns, the teacher must have additional skills and methods to accommodate differences in the learning patterns of students and to take into account individual differences throughout choosing learning styles and strategies during the educational situation (Abdel \& Medhat, 2016; Fuqaha, 2002).

\section{Theoretical Background}

The term of learning patterns or learning styles emerged in the early 20th century, when some theories and personal classifications of individual differences appeared among people. It was used firstly by Carl Young in 1927 in his theory of primary patterns. Several definitions of the concept of educational style have emerged, including the American Society for Training and Development (ASTD), which referred to it as "a theoretical and practical concept that indicates how the learner acquires his/her knowledge or how to change his/her behavior." The National Association of American High School Principals defined the learning pattern more comprehensively as "a combination of mental, emotional and physical characteristics that act as relatively consistent indicators of the learner's behaviors during his reception, interaction and responsiveness to the educational environment." Al-Zayyat (2004) defined it as "cognitive, motivational, psychological, and temperamental indicators that reflect how the learner receives information, how he/she processes and interacts with it, and responds positively to it through the educational environment". Al-Qatami (2000) defined it as "the way an individual uses information to organize and manipulate information, including transformation, integration and reconstruction of knowledge into individual experiences" (Rawashdeh et al., 2010, p. 361).

From the previously mentioned definitions and other, there is a kind of agreement that learning patterns refer to ways students interact and handle information, perceived and absorbed, and their ability to retain and retrieve it; these patterns are differed from one student to another, making the same education effective with some students and ineffective with others, which confirms the need to the existence of diversify in their learning methods and taking into account the individual differences between them in order to achieve the desired learning, and raise the level of their academic performance, commensurate with their abilities and interests on the basis that their final level of achievement depends on the way that the learner is employed to perceive and process information.

As a result of the increasing interest of educational researchers in the study of learning patterns, many models emerged for classifications of learning patterns. The most prominent of these is the VAK model of sensory-based cognitive learning patterns. It was developed by psychologists in the 1920 s to classify the most common patterns and methods of education among people. It classifies learners into three sections (auditory, visual, and kinesthetic); Visual style in learning: Its author depends on learning through visual perception and visual memory; he/she learns better by seeing educational material, such as drawings and shapes, directly or through projectors, and using actions such as "show me" or "let me see" as he learns; the auditory style is a pattern that depends on the auditory perception of the subject by listening to the teaching material: lectures, discussions, oral dialogues, and using actions such as "tell me" through learning, while the kinesthetic style depends on practical tactile perception, learning ideas and meanings through practice, experience and discovery, modeling, experimenting and motor activities, and it uses actions such as "let me try" or "how to feel" through learning, since this style is adopted in the present study. A study conducted by Miller (2001) found that $29 \%$ of all students in primary and secondary schools learn through visual style , 34\% learn through auditory style, and 37\% learn better through kinesthetic style (Fleming \& Bonwell, 2002; Fayombo, 2015).

There is another example for Dunn \& Dunn that focused on the cognitive pattern, and exploits both the left and right sides of the brain, which emphasizes that learners learn better in different ways. Accordingly, a model was created, in which it is involved 20 elements that were included in six main dimensions: (Perceptual, Environmental, Emotional, Sociological, Physiological, and Psychological dimensions). Thus, individuals were divided according to their tendencies to: global, analytical, impulsive, and reflective. Moreover, Kolb's model (kolb, 1984), which is derived from Piaget theory and the theory of experiential learning; it classifies learning patterns into four types based on the quality of learning experiences: A. Concrete Experience: an individual relies on sensory experiences in learning. B. Reflective observation: the author tends to process information through internal reflection, c. Active Experimentation Style: Active Experimentation tends to actively address external stimuli and experiences. D. Abstract Conceptualization: Its owner tends to process information at the symbolic and conceptual level (Yaqoob et al., 2016; Amiri \& Ahmad, 2015; Al-Nazeer, 2015).

While McCarthy's model of formality is based on David Kolb's theory that indicates individuals learn new information and knowledge, and face new experiences in two ways: feelings or thinking. Accordingly, the two dimensions of learning were divided into four main types: A. Imaginary learners: prefer learning strategies 
associated with listening and speaking. B. Analytical learners: prefer learning strategies associated with viewing, analysis and classification, and tends to abstract thinking. C. Logical learners: prefer a learning strategy based on experimentation and sensory interaction with experiences. D. Dynamic learners: prefer research and exploration, learning strategies based on modification, and love of adventure and creativity (Al-Shoura \& Jawaldeh, 2012; Aldmour, 2008).

Another model is known as the VARK model of Fleming and Bonwell. This model classifies learning patterns into four patterns that focus on cognitive sensory means, in which the learner prefers to process his knowledge and experiences with the aim of learning. These are: A. Visual style: the author learns depending on visual perception of the educational material. B. Auditory style: the author learns depending on auditory perception. C. Reading style: The author learns through depending on the reading and written ideas and meanings. D. Kinesthetic style: The author learns the concepts and meanings of tactile perception through experience and discovery, and they prefer real and natural situations and models (Al-Jarrah, 2015; Vaishnav, 2013).

As shown by the previous classifications of learning patterns, and based on research and studies that have demonstrated the importance of attention to these patterns to provide better learning opportunities in university education (Yaqoob et al., 2016; Al-Nazeer, 2015; Ghafari et al., 2013). Or in the general education stages (Fayombo, 2015; Vaishnav, 2013; Miller, 2001), this is achieved through training and encouraging teacher to depend on the diversify of educational strategies, methods and activities to suit their students' preferred learning patterns and to help them learn better according to these patterns to overcome their learning difficulties, develop their abilities and raise their academic level, and improve their attitudes towards learning.

\section{Research Problem}

Since teachers in different stages of education have large numbers of students in the classroom who are different in their abilities, tendencies and educational patterns, but often teach them all in one way without taking into account their differences in the learning styles they prefer; and the development of their thinking during the academic stages; this may negatively affect the quality of outputs of teaching process. In view of the reality of contemporary teaching in the stages of education in general and linked to the challenges facing the educational process in the twenty-first century, educational institutions should have been engaged in research and reflection on the development of effective educational mechanisms that would ensure the generation of an educational setting and make it able to adapt to the changing times of the age; this can only be achieved through the development of modern teaching models and strategies, and the attempt to get rid of traditional models that do not reveal the abilities and potential of students, and do not take into account the individual differences between their learning patterns.

Based on the differences between the results of the previous studies related to the subject of the study and the recommendations made by some recent studies (Meshack, 2015; Fayombo, 2015; Yaqoob et al., 2016), which pointed to the need for conducting further studies on learning patterns in different stages and educational environments. This study aims to identify the cognitive learning patterns (VAK) preferred by students who completed secondary school, and their impact on their achievement in physics, and compare the results obtained through this study with the results of previous studies concerning this area, in order to give an opportunity to learn for all students according to their preferred learning styles.

\subsection{Research Questions}

This study addresses the following research questions:

- What types of cognitive learning are preferred by secondary school students admitted to King Saud University?

- Are the types of cognitive learning preferred by secondary school students admitted to King Saud University different according to gender at the level of $(\alpha=0.05)$ ?

- Are there any statistically significant differences at the level of $(\alpha=0.05)$ in the average achievement of secondary school students in physics attributed to cognitive learning style?

\section{Research Significance}

The importance of the current study stems from the new information that includes the detection of preferred learning patterns among secondary students who have been admitted to the university level, according to a scale prepared by the researcher; moreover, it is expected that the results of this study will contribute to determining the impact of students' preferred learning style on their academic achievement, as well as encouraging the university administration to provide a stimulating university environment for its new students by paying attention to 
providing the training needs and professional requirements of faculty members to enable them to take into account the individual differences between their students in determining the educational objectives, the educational content, the methods and strategies, the appropriate educational needs of the students according to their abilities; which will achieve their satisfaction and increase their motivation and attitudes towards university learning and to keep abreast of the scientific and technological progress in order to achieve what is known as effective university teaching with its qualitative educational outputs.

\section{Study Terms}

- $\quad$ Cognitive Learning Patterns (VAK): The learning patterns that are dependent on the senses and preferred by the learner in education and it is represented by visual style, in which the learner depends on visual perception in education. The Auditory style: the learner depends on the auditory perception, and kinesthetic style, in which the learner depends on the practical tactile perception. The pattern of learning of the sample members in this study is determined by the highest total of their grades on the three patterns in the scale of learning patterns prepared by the researcher, since the learning pattern of the learner is the highest total in grades according to its compatibility with its wishes and needs.

- Student's academic achievement: The final grade in physics that the sample members have got at the end of the second semester of the third secondary grade.

- Physics: is the subject of physics taught to all secondary students and in all schools in Saudi Arabia at the last level of the third secondary grade.

\section{Limitations of the Study}

The results of this study are determined by the population of the study and its sample and the method of their selection, which was limited to a sample of students who completed the requirements of the secondary stage and they were accepted in the Deanship of the common first year at King Saud University in Riyadh, beginning of the first semester of 2017/2018 in order to reveal their favorite learning patterns. Therefore, the results are valid for generalization in the statistical community of this study. It is also determined by the accuracy and objectivity of the sample members in response to the scale of learning patterns applied to them.

\section{Previous Studies}

Yaqoob et al. (2016) conducted a study which aimed at identifying the prevalent patterns of learning among the students of the Faculty of Education at Kuwait University and its relation to some variables. The sample is consisted of 214 students who were chosen by random stratified method. The results of the study showed that the cognitive pattern is the most common pattern of learning among the students of the Faculty of Education. Moreover, the results showed that there were statistically significant differences in the cognitive pattern attributed to gender variable and in favor of females, while there were no statistically significant differences attributed to other variables (academic year, scientific specialization, and general average). Based on the results, the study recommended that teachers should be sensitized and trained to observe learning patterns and conduct further studies in this field.

Meshack (2015) conducted a master's study which aimed at determining the relationship between learning patterns (VAK) and academic achievement among secondary students in Kenya. The study sample is consisted of 280 students selected from 4 secondary schools with varying performance (two high performance schools, two low performance schools); to achieve the aim of the study, the researcher used a tool to detect the students' audio, visual and kinesthetic learning patterns. After analyzing the data, the results showed that the majority of students preferred the three types of learning, followed by students who prefer the types of audio and visual learning, while the kinesthetic learning pattern was the least favored among students. The results also showed that there are no statistically significant differences attributed to the gender variable between students' learning patterns and their academic achievement, whether for groups with low or high achievement, while the results showed a strong correlation between the academic achievement and the learning patterns of students who prefer the three educational styles.

Another study conducted by Fayombo (2015) aimed at identifying educational patterns (VAK), teaching strategies (video, games, role play, discussion, teams) and their impact on academic achievement among a sample of undergraduate students in Educational Psychology specialization at university at West Indies, consisting of 171 male and female students. To achieve the objectives of the study, the researcher prepared three tools: the questionnaire of active learning strategies, the survey of learning patterns, and the detection of academic achievement of students. After the application and analysis of the study tools, the results showed that students prefer visual, auditory, kinesthetic patterns, and then multiple patterns and that the majority of students prefer 
learning strategies used within the classroom. The results also revealed a statistically significant effect of learning patterns and teaching strategies on the academic achievement of students. Based on these results, the study recommended the need to diversify in teaching strategies to accommodate differences in students' learning patterns and to increase their academic achievement in educational psychology.

Al-Nazeer (2015) conducted a study which aimed at measuring the types of learning pattern and their ratios according to the Honey and Mimford scale in a sample of new students of several majors at King Saud University, and the correlation between the learning pattern and the level of general abilities and academic achievement in mathematics course (140). The results showed an indirect reverse correlation between the models of active and comprehensive learning, the students' grades in mathematics and general abilities, and the existence of a positive correlation between the models of learning and the theoretical and practical grades of students in mathematics and general abilities. Accordingly, the study recommended the there is a need to take into account the patterns of learning in university teaching in general, and in teaching of new students in particular, to diversify the methods and strategies of university teaching, and to include mathematics tests and public abilities in line with those patterns.

Another study conducted by Vaishnav (2013) aimed at analyzing the prevailing kinesthetic, auditory, and visual patterns of learning among middle school students. The study sample is consisted of 200 students from $(9,10,11)$ grades in Maharashatra. The results of the study showed that the kinesthetic pattern is the most common one comparing with audio and visual patterns among students. The results also showed a statistically significant correlation between learning patterns and academic achievement. There was a high correlation between kinesthetic pattern and academic achievement, followed by a lower correlation between visual learning and academic achievement. While the results showed a low positive correlation between the pattern of audio learning and academic achievement.

Ghafari et al. (2013) conducted a study which aimed at studying and analyzing different learning patterns and their relation to academic achievement among medical students in the basic science program at Tabriz University of Medical Sciences. The sample consisted of all students of the basic science program at Tabriz University of Medical Sciences in 2011-2012. The researchers used a questionnaire that included demographic surveys and information, and Kolb's standard questions for learning patterns. The results showed that after the application and analysis of the study tool, there was no significant correlation between students' academic achievement and their learning patterns, and that the majority of students preferred convergent learning styles; thus adopting interactive teaching; using lessons, running simulations and laboratory activities; and encouraging students to think and analyze problems and issues will effectively contribute to the continuity of their educational lifecycle.

In another study conducted by Alwan (2012), the aim was to identify the preferred learning methods of high school students in Ma'an city in Jordan and its relationship with gender and specialization variables. The study sample consisted of 220 students from second grade secondary school. To achieve the goal of the study, the researcher used the list of advanced learning methods by Oliver (1995). The results of the study showed that the most preferred learning methods for students is the audio style, followed by visual style, and the least favored among students is the kinesthetic pattern (touch). Moreover, the results showed that the students of the scientific branch prefer visual and kinesthetic learning methods, while students in the literary branch prefer audio learning methods. Based on the results, the study recommended that teachers should focus on identifying students' preferences for learning methods and planning to teach them according to them.

Khan and Iqbal (2012) conducted a study which aimed at detecting the effect of learning patterns on achievement of distance learners, specifically the Master students of Education program at the University of Iqbal in Islamabad, were randomly selected and the learning patterns were measured using the (Grasha-Riechmann Scale) for student learning patterns. The results of the study showed that the majority of the students' learning styles tend to the cooperative learning style, followed by the participant, the independent, the competitive, and then the subordinate and introverted pattern. The results also showed that there is no correlation between learning and achievement patterns and there is a negative correlation between Introvert learning pattern and achievement

Thomas (2009) referred to in Yaqoob et al. (2016) conducted an analytical study which aimed at detecting the impact of gender and the level of achievement on learning patterns for students in grades 7, 9 and 11 . The study sample consisted of 269 male and female students who applied the study tool (questionnaire) to achieve the study objectives. After analyzing the data, the results showed that the students' need for instruction, to eat and drink during the study, their preference for the auditory and kinesthetic pattern, the Students with intermediate achievement's preference for the audio pattern and their need for instructions and study in the morning and they think and hope a lot and are characterized by perseverance, while the students with low achievement preferred 
bright lighting and hearing voices in the background while they study new and difficult information, as well as the presence of power holders next to them. The results showed that females were characterized by analytical thinking and decision-making, while males showed their need for instruction, preferred eating, and learning alongside their peers.

Bilawi (2006) conducted a study which aimed at identifying the preferred learning methods and multiple intelligences among Yarmouk University students. The study sample is consisted of 861 male and female students. To achieve the aim of the study, the researcher used a measure of preferred learning methods and another for multiple intelligences. The results of the study showed that the method of audio learning was more preferred among the sample, followed by the method of kinesthetic (touch) learning pattern came in the second place, then the pattern of visual learning. The results also revealed that there is a correlation between the learning methods and multiple intelligences. Accordingly, the study recommended the importance of diversifying the use of different educational methods to suit most students.

Al-Omran (2006) conducted a study which aimed at identifying the differences between the primary stage students with a visual and dynamic style to the behavioral characteristics of learning and examined the relationship between the visual, auditory and kinesthetic learning styles and the academic achievement of the ordinary class and the class of learning difficulties in Bahrain, in which their numbers reached 230 male and female students. The results showed that there are significant differences in the three learning methods (visual, auditory and kinesthetic) in the behavioral characteristics of learning difficulties. There was also a significant gender impact and interaction between gender and the educational stage of audio learning style in favor of females and there was an impact for the kinesthetic learning style in favor of male. The results also showed a positive correlation between educational attainment and visual learning method, and a negative correlation between learning achievement and the kinetic learning method for the normal students and the learning difficulties category.

By reference to the previous studies, many differences and agreements were found in their results. The results of some studies related to the university stage such as (Yaqoob et al., 2016; Al-Nazeer, 2015; Ghafari et al., 2013) agreed that there is no statistical significance and correlation relationship between the styles of learning and academic achievement among university students. The results of other studies on the same stage (Fayombo, 2015) showed a statistically significant effect of learning styles on achievement. As for the stages of general education (intermediate and secondary), the results of some studies (Thomas, 2009; Vaishnav, 2013; Omran, 2006) showed that there is a different correlation between the learning patterns and academic achievement of middle and high school students, while the study of (Meshack, 2015) showed that there is a strong correlation between the learning patterns and academic achievement of secondary students who prefer the three educational patterns (VAK).

As shown in previous studies; there is an agreement between the results of the studies of (Miller, 2001; Vaishnav, 2013) on the preference of students of the intermediate and secondary stage of the kinesthetic pattern, which is the most common one, followed by the auditory style, then the visual style. While the results of other studies are differed in terms of students' preference for learning patterns, since Al-Aloun's (2012) study indicated the preference of middle school students for the audio style followed by visual style, then the kinesthetic style. (Fayombo, 2015) study pointed out that university students prefer visual style, then auditory and kinesthetic styles, then multiple styles. While the results of the studies of (Belaawi, 2006; Thomas, 2009) indicated that students preferred to use audio and visual learning styles more than they did with the visual style, although they differed in the academic stage (university/intermediate and secondary). Most of the studies (Yaqoob et al., 2016; Fayombo, 2015; Al-Nazeer, 2015) have agreed on the need to expose different learning styles to students at all levels of education, and to sensitize and train teachers to observe the learning patterns of their students and identify their preferences in Learning process and to diversify strategies and teaching methods to accommodate the difference in the patterns of student learning, and increase academic achievement.

\section{Methodology and Design}

This chapter includes a description of the study population and its sample, the tools used in it, the procedures for applying them and correcting them, verifying their validity and stability, and other statistical treatments that were followed to answer the study questions.

\subsection{Study Population and Sample}

The study population consists of all secondary students who were admitted to the scientific track at King Saud University before the beginning of the first semester of the academic year (2017/2018), in which their numbers are (4300) male and female students. . The sample of the study is consisted of (626) male and female students who were randomly selected from the deanship of common first year at King Saud University. 


\subsection{Study Tools}

To achieve the objectives of the study, the researcher prepared a measure for the detection of the three types of cognitive learning (visual, auditory, kinesthetic) preferred by the sample members; after going to the previous literature on learning patterns and classifications as well as Check out some online e-learning patterns' scale; so that each item contains three options each belonging to one of the three types of cognitive learning, and according to this measure, the type of learning that students prefer is determined through calculating the number of selected items and developed for this pattern. To ascertain the authenticity of the virtual content of the tool, it was presented to seven referees; five professors in the curricula and methods of teaching, professor in psychology, and another in measurement and evaluation in order to ascertain the accuracy of the wording and clarity of the items of the tool and its appropriateness to the purpose for which it was prepared; the necessary amendments were made in the light of the referees' observations.

To verify the validity of the internal consistency of the scale, the Pearson correlation coefficient was calculated between the scores on the expressions and the total scores on the instrument. Table 1 illustrates this:

Table 1. Pearson correlation coefficient between scores on tool expressions and total score on tool

\begin{tabular}{cccccc}
\hline Expression & $\begin{array}{c}\text { Pearson correlation } \\
\text { coefficient }\end{array}$ & $\begin{array}{c}\text { Statistical } \\
\text { significance }\end{array}$ & expression & $\begin{array}{c}\text { Pearson correlation } \\
\text { coefficient }\end{array}$ & $\begin{array}{c}\text { Statistical } \\
\text { significance }\end{array}$ \\
\hline 1 & $.429^{* *}$ & 0 & 9 & $.791^{* *}$ & 0 \\
2 & $.725^{*}$ & 0 & 10 & $.345^{* *}$ & 0 \\
3 & $.735^{* *}$ & 0 & 11 & $.603^{* *}$ & 0 \\
4 & $.507^{* *}$ & 0 & 12 & $.571^{* *}$ & 0 \\
5 & $.710^{* *}$ & 0 & 13 & $.486^{* *}$ & 0 \\
6 & $.457^{* *}$ & 0 & 14 & $.401^{* *}$ & 0 \\
7 & $.420^{* *}$ & 0 & 15 & $.625^{* *}$ & 0 \\
\hline
\end{tabular}

* Function at the level of 0.05 .

** Function at level of 0.01 .

It is observed from Table 1that Pearson's correlation coefficient between the scores on tool expressions and the total score on the instrument is all statistically significant; thus, reflecting the validity of the tool that reveals cognitive learning patterns.

To verify the stability of the tool, the Cronbach's Alpha coefficient was used, and the stability coefficient was 0.71 , which means that the tool has good stability.

\subsection{Study Procedures}

To achieve the objectives of the study, the researcher took the following steps:

1) Prepare the items of the tool to detect the patterns of learning, and to verify its validity and stability before applying it to the study sample.

2) Upload the scale electronically through Google Drive, select the link of access to the tool, and then send it to sample members to respond to it, and to identify their preferred learning patterns.

3) Collect and analyze responses through appropriate statistical analysis to answer the study questions.

\section{Results}

The statistical analysis conducted on the study data revealed the following results ordered according to their questions:

9.1 Results Related to the First Question: What Types of Cognitive Learning Preferred by Secondary School Students Admitted at King Saud University?

In order to identify the learning patterns of students admitted to the scientific track at King Saud University, the frequency and percentage of respondents' responses were calculated on the learning patterns scale. The chi square test $\left(x^{2}\right)$ was also calculated to identify the extent of differences in ratios between learning patterns. The results were as shown in Table 2. 
Table 2. Frequency and percentage of learning patterns among the sample member, and the results of the chi square test $\left(x^{2}\right)$

\begin{tabular}{ccccc}
\hline Learning pattern & Frequency & Percentage & $\begin{array}{c}\text { chi square } \\
\text { test }\left(x^{2}\right)\end{array}$ & Statistical significance \\
\hline Visual & 358 & 57.2 & & \\
Kinesthetic & 86 & 13.7 & 182.3 & 0.00 \\
Auditory & 182 & 29.1 & & \\
Total & 626 & 100 & & \\
\hline
\end{tabular}

It is observed from Table 2 that there are apparent differences between frequency and percentage of respondents' responses to the learning patterns scale. Given the value of the chi square $\left(x^{2}=182.3\right)$, it is found that the differences between the ratios of the learning styles preferred by the sample of the study sample were statistically significant as they were as follows (visual $=57.2 \%$, auditory $=29.1 \%$, kinesthetic $=13.7 \%$ ).

9.2 Results Related to the Second Question: Are the Patterns of Cognitive Learning Preferred by Secondary School Students Admitted at King Saud University Different According to Gender at the Level of Significance (A $=0.05)$ ?

To answer the question, the chi square test of homogeneity $\left(x^{2}\right)$ was used. The frequency and percentages of frequency were calculated for each cell resulting from the intersection between the learning mode variable (kinesthetic/visual/auditory) and the gender variable (male/female). Table 3 shows the results.

Table 3. Frequency and percentage of frequency of learning patterns in the sample according to the differences in gender and the results of the chi square test $\left(x^{2}\right)$

\begin{tabular}{ccccccc}
\hline \multirow{2}{*}{ Learning pattern } & \multicolumn{2}{c}{ Gender } & \multirow{2}{*}{ Total } & chi square & Statistical significance \\
\cline { 2 - 4 } kinesthetic & Frequency & 62 & 24 & 86 & & \\
& $\%$ & $13.7 \%$ & $13.8 \%$ & $13.7 \%$ & & \\
Visual & Frequency & 242 & 116 & 358 & & \\
& $\%$ & $53.5 \%$ & $66.7 \%$ & $57.2 \%$ & & \multirow{2}{*}{ Female } \\
Auditory & Frequency & 148 & 34 & 182 & 11.32 & \\
& $\%$ & $32.7 \%$ & $19.5 \%$ & $29.1 \%$ & & \\
Total of frequencies & & 452 & 174 & 626 & & \\
Total of $\%$ & $72.2 \%$ & $27.8 \%$ & $100.0 \%$ & & \\
\hline
\end{tabular}

It is observed from table 3 that there are apparent differences in the frequency and percentage of frequencies of learning patterns preferred by the sample attributed to the gender variable, where the value of the chi square $\left(x^{2}=\right.$ $11.32)$ is statistically significant at the statistical significance level $(\alpha=0.05)$.

9.3 Results Related to the Third Question: Are There Statistically Significant Differences at the Level of Significance $(A=0.05)$ Between the Average Achievement of Secondary School Students in Physics Attributed to the Type of Cognitive Learning?

To answer this question, the arithmetical averages and standard deviations of the students' scores were calculated in physics, the ONE WAY ANOVA test was carried out, and the remote comparisons were performed to judge the significance of the differences between these averages according to the learning patterns variable (visual/auditory/kinesthetic),(male/Female). Tables 4, 5, 6, 7, 8, 9 illustrate these results.

Table 4. Mathematical averages and standard deviations of male degrees in physics according to learning pattern variable

\begin{tabular}{cccc}
\hline Learning pattern & Number & Average & Standard deviation \\
\hline Kinesthetic & 182 & 86.74 & 4.79 \\
Audio & 86 & 72.70 & 5.15 \\
Visual & 358 & 79.91 & 5.70 \\
\hline
\end{tabular}


Table 4 shows that there are apparent differences in the Mathematical averages of male scores in physics according to the learning pattern variable (visual, auditory, kinesthetic). To detect the significance of these differences, the ANOVA was used. Table 5 shows these results.

Table 5. Results of the analysis of ANOVA to detect the existence of statistically significant differences between the Mathematical averages of male scores in physics according to the learning pattern variable

\begin{tabular}{cccccc}
\hline Source of variation & Total squares & Freedom degree & Average squares & F value & Statistical significance \\
\hline Between groups & 12328.710 & 2 & 6164.355 & \multirow{2}{*}{153.748} & \multirow{2}{*}{0.00} \\
\cline { 1 - 4 } Within groups & 18002.156 & 449 & 40.094 & & \\
\hline
\end{tabular}

It is observed from Table 5 that the value of the statistical test (f) was 153,748 , which is a statistically significant value. This indicates the significant differences between the arithmetical averages of the students' grades in physics according to the learning patterns variable (visual, auditory, kinesthetic). To discover the sources of the differences between the mathematical mean scores of the males in Physics according to the learning pattern variable, the LSD test was conducted for post- tests, and Table 6 shows the results of this test.

Table 6. The results of the LSD test to examine the significance of differences between the arithmetic mean of the scores of Males in physics attributed to the learning pattern variable

\begin{tabular}{cccc}
\hline \multicolumn{2}{c}{ Learning pattern } & The difference between the two averages & Statistical differences \\
\hline Kinesthetic & Visual & $6.83^{*}$ & 0.00 \\
Kinesthetic & Auditory & $14.03^{*}$ & 0.00 \\
Visual & Auditory & $7.21^{*}$ & 0.00 \\
\hline
\end{tabular}

It is observed from Table 6 that the differences between the mean scores of physics for males who prefer the kinesthetic pattern and the mean scores of males with the visual and auditory style were statistically significant at $(\alpha=0.05)$ and for students who prefer the kinesthetic pattern. For males who prefer visual style, the average score of students who prefer the auditory pattern was statistically significant at $(\alpha=0.05)$ and for students who prefer visual style.

In order to determine the effect of the learning pattern on female achievement in physics, the mean and standard deviations of female scores in physics were calculated according to the learning pattern variable, as shown in Table 7.

Table 7. Mathematical averages and standard deviations of female scores in physics according to the learning pattern variable

\begin{tabular}{cccc}
\hline Learning pattern & Number & Average & Standard deviation \\
\hline Kinesthetic & 80 & 96.91 & 8.45 \\
Auditory & 15 & 84.00 & 15.89 \\
Visual & 79 & 90.51 & 16.38 \\
\hline
\end{tabular}

Table 7 shows that there are apparent differences in the mathematical averages of female scores in physics according to the learning pattern variable (visual, auditory, kinesthetic). To detect the significance of these differences, the ANOVA was used. Table 8 shows these results.

Table 8. Results of the analysis of the single variance to detect the existence of statistically significant differences in the mathematical averages of the female grades in the physics according to the learning pattern variable

\begin{tabular}{cccccc}
\hline Source of variation & Total squares & Degrees of freedom & Average squares & f value & Statistical significance \\
\hline Between groups & 3244.252 & 2 & 1622.126 & \multirow{2}{*}{14.273} & 0.01 \\
Within groups & 19434.415 & 171 & 113.652 & & \\
\hline
\end{tabular}

Table 8 shows that the value of the statistical test (f) was 14,273 , which is a statistically significant value. This 
indicates the fundamental differences between the mathematical averages of the female grades in physics according to the learning mode variable (visual, auditory, kinesthetic). In order to discover the sources of differences between the mathematical averages of female scores in physics according to the learning pattern variable, the LSD test was conducted for post hoc tests, and Table 9 shows the results of this test.

Table 9. The results of the LSD test to examine the significance of differences between female Arithmetic averages

\begin{tabular}{cccc}
\hline \multicolumn{2}{c}{ Learning pattern } & The difference between the two averages & Statistical significance \\
\hline Kinesthetic & Visual & $6.40^{*}$ & 0.00 \\
Kinesthetic & Auditory & $12.91^{*}$ & 0.00 \\
Visual & Auditory & 6.51 & 0.00 \\
\hline
\end{tabular}

Table 9 shows that the differences between the averages of the physics scores of females who prefer the kinesthetic pattern and the average scores of females who prefer the visual and auditory style were statistically significant at the $\alpha=0.05$ level in favor of those who prefer the kinesthetic pattern. The table also shows that the differences between the mean scores of females who prefer the visual pattern and the average scores of those who prefer the auditory pattern were statistically significant at $(\alpha=0.05)$ in favor of females who prefer the visual pattern.

\section{Results Discussion}

The results in Table 2 showed statistically significant differences between the learning patterns preferred by the study sample (visual $=57.2 \%$, auditory $=29.1 \%$, kinesthetic $=13.7 \%$ ). This result is agreed with some previous studies' results, such as Fayombo (2015), which indicated the preference of undergraduate students for visual, auditory, and kinesthetic learning. The study of (Alalwan, 2012) showed that the students of the scientific branch prefer visual learning methods. As well as Vaishnav (2013) study, whose results indicate that the preference of secondary students for the kinesthetic learning pattern is low. This result may reflect the nature of the teaching that was available to students in the secondary and previous stages that is represented in the inclusion of educational situations in pictures and drawings, models and paintings, writing on the blackboard, and dialogue and discussion during learning. But this does not mean that there are no other preferred learning styles that have an impact on students' achievement in the event of a change in the learning environment, especially since these students have moved to a university that differs in their environment from the general education levels and they are accepted in the scientific branch. This requires teachers at the undergraduate level to diversify into methods and strategies within the classroom to ensure that the needs of all students are met according to the learning styles they prefer, to increase their motivation and motivate them to learn.

As shown in Table 3 there are statistically significant differences between the percentages of learning styles preferred by the study sample members attributed to gender variable. Since it is observed that males prefer the audio pattern (32.7\%) more than females (19.5\%), while females were more favorable to visual pattern $(66.7 \%)$ more than males $(53.5 \%)$; this indicates that male students tend to learn through dialogue, discussion, auditory comprehension and auditory methods more than females. This may be attributed to the male nature and their need for communication skills with the community inside and outside the university environment, and the focus of their teachers on dialogue and discussion with them in and outside the educational situation, while females tend to learn by observation and use of visual aids, drawings and images more than males. This can be attributed to the nature of females and their interest in images, shapes, colors and landscapes, in addition to the nature of the learning environment in both males and females, and the availability of means and equipment as well as the willingness of teachers to choose the best ways and appropriate methods according to the content taught by the teacher. They have the desire to learn through audiovisual perception, and visual perception, which requires the need to diversify methods and strategies by teachers. These results are agreed with some studies' results such as (Bilawi, 2006) and (Alawan 2012), whose results showed students' preference for audio learning more than visual and kinesthetic pattern. The results of some studies, such as Fayombo (2015), showed that students prefer the visual more than auditory and kinesthetic patterns. These preferences may be influenced from time to time by several factors: learning environment, provision of equipment, students' ability to experiment and solve problems, achievement, and other factors.

As for the effect of the pattern of learning on students' achievement in physics, the results showed that the most achievable students (males and females) are those who prefer the kinesthetic pattern, followed by students who prefer visual mode, while students who prefer the audio style are the least achievable students. This may be attributed to the nature of physics that students have difficulty through learning it (Al-Hajhoj, 2013). This 
motivates teachers to engage students in their activities to make it easier for them to learn ideas and subjects through experience, discovery and manual work and this is typical of students with a kinesthetic style, and thus has more ability to achieve comparing with their peers who prefer visual and audio learning. This finding is agreed with the results of some studies (Fayombo, 2015; Meshack, 2015) that showed a statistically significant effect of learning patterns on achievement, While it differed with other studies (Jafar, 2016; Nazir, 2015; Ghafari et al., 2013), in which its results indicated that there was no statistically significant correlation between the learning patterns and the academic achievement of university students. Therefore, the teachers at the university should be aware of the nature of the subjects they study, the nature of the disciplines of their students, and the selection of the best methods and strategies for implementing the content, while taking care to diversify them as required by the situation to take into account the individual differences between their students.

\section{Recommendations}

In light of the results of the study, the researcher recommends the following:

1) Encourage teachers to diversify university teaching strategies and methods to suit the learning patterns that their students prefer, especially new university students, to motivate them to learn in the university environment.

2) Providing the training needs and professional requirements of faculty members, to enable them to take into account the individual differences between their students in their identification of educational objectives, content, methods and strategies.

3) Conduct more studies on the different learning styles of students, and educate teachers about the importance of taking into account their students' learning patterns and their role in achieving effective university teaching.

\section{References}

Abdel, M., \& Medhat, A. (2016). The impact of the use of learning style strategy on some learning outcomes for students of the Education Division. Scientific Journal of Physical Education and Sport, 76, 408-430.

Al-Damour, M. M. K. (2008). Relationship between the Learning Patterns of Southern Jordan University Students with Academic Achievement and Academic Self-efficacy (PhD Thesis, University of Jordan).

Al-Foqaha, N. E. (2002). Patterns of learning of secondary school students belonging to the Directorate of Education of Amman II in Jordan and their relationship to gender, specialization, level of educational attainment and family income. Dirasat Human and Social Sciences, 29(1), 1-23.

Al-Hajhoj, Y. (2013). The nature of physics and its relation to the teaching methods of physics teachers in secondary schools in Palestine. Journal of Al-Aqsa University: Series of Human Sciences, 17(2), 177.

Aljarrah, A. A. (2015). Measuring the preferred learning styles of students of the Faculty of Educational Sciences at Mutah University and its relation to some variables. Journal of the Faculty of Education, 1(163), 319-412.

Al-Nazeer, M. (2015). Patterns of learning and their relation to the level of general abilities and academic achievement in mathematics among new students at King Saud University. Journal of Education and Psychology, 83-100.

AL-Omran, J. I. (2006). Methods of learning and their relation to behavioural characteristics of learning difficulties and academic achievement in a sample of Bahraini students in basic education. Educational Journal, 20(78), 75-111.

Alwan, A. (2012). The preferred learning methods of high school students in Ma'an in Jordan and its relation to gender and specialization. University of Sharjah Journal for Humanities and Social Sciences, 7(special issue), 269-299.

Ameri, A., \& Ahmed, R. (2015). The Effect of Learning Patterns (Dunn \& Dunn Model) in the Collection of Art Education for Fifth Grade Students. Basic Education College Magazine For Educational and Humanities Sciences, 20, 566-592.

Bilawi, M. (2006). The preferred learning methods and multiple intelligences among Yarmouk University students (Unpublished doctoral dissertation, Yarmouk University).

Fayombo, G. (2015). Learning Style, Teaching Strategies and Academic Achievement among some psychology Undergraduates in Barbados. Caribbean Educational Research Journal (The University of the West Indies Cave Hill Campus), 3(2), 46-61. https://doi.org/10.1037/e734362011-095 
Fleming, N. D., \& Bonwell, C. C. (2002). How do I learn Best: A student guide to improved learning? Colorado: Green Mountain Falls.

Ghafari, R., Ranjbarzadeh, F., Azar, E., \& Hassanzaden, S. (2013). The Analysis of Learning Style and Their Relationship to Academic Achievement in Medical Students of Basic Science Program. Res Dev Med Educ, 2(2), 73-76.

Khan, J., \& Iqbal, M. J. (2016). Effect of Learning Style on Achievement of Distance Learners. Dialogue (Pakistan), 11(3).

Meshack, N. M. (2015). A Correlation Study between Learning Style and Academic Achievement among Secondary School Student in Kenya (Master of Education Research, University of Nairobi, Kenya.)

Miller, P. (2001). Learning Style: The multimedia of the mind. Educational Resources Information Center (ED 451140).

Rawashdeh, I., Nawafallah, W., \& Omari, A. (2010). Patterns of Learning among ninth Grade Students in Irbid, and their Impact on their Achievement in Chemistry. The Jordanian Journal of Educational Sciences, 6(4), 361-375.

Shoura, Z. M., \& Jawalda, F. E. (2012). Patterns of Learning and their Relativity to Achievement in Learning Disabilities Students (Master Thesis, Amman Arab University).

Vaishnav, R. S. (2013). Learning Style and Academic Achievement of Secondary School Students. Voice of Research, 1(4), 1-4.

Yaqoob, J., Alkhazi, F., \& Safar, A. (2016). Patterns of learning among the students of the Faculty of Education at the University of Kuwait and its relation to some variables: case study. Journal of Educational and Psychological Sciences, 17(4), 151-185. https://doi.org/10.12785/jeps/170405

Zoghul, E., \& Hamamid, S. (2010). The Psychology of Class Teaching. Amman: Dar Al Masirah for Publishing and Distribution.

\section{Copyrights}

Copyright for this article is retained by the author(s), with first publication rights granted to the journal.

This is an open-access article distributed under the terms and conditions of the Creative Commons Attribution license (http://creativecommons.org/licenses/by/4.0/). 